\title{
Editorial: Looking Through the Mesh of a Net: The Challenge of Socio-Ecological Systems
}

\author{
Antonio Bodini ${ }^{1 *}$, Jeffrey M. Dambacher ${ }^{2}$ and Ferenc Jordán ${ }^{3}$ \\ 'Department of Chemistry, Life Sciences and Environmental Sustainability, University of Parma, Parma, Italy, \\ ${ }^{2}$ Commonwealth Scientific and Industrial Research Organisation (CSIRO), Hobart, TAS, Australia, ${ }^{3}$ Democracy Institute, \\ Central European University, Budapest, Hungary
}

Keywords: socio-ecological systems, social networks, qualitative modeling, scenario analysis, participatory approach

\section{Editorial on the Research Topic}

\section{Looking Through the Mesh of a Net: The Challenge of Socio-Ecological Systems}

\section{PREMISE}

Since the socio-ecological systems (SES) framework ${ }^{1}$ came into being more than 20 years ago (Colding and Barthel, 2019), it has firmly taken hold conceptually (Bodin and Tengö, 2012; Scotti et al., 2021). Yet in practice it is still in its adolescence, although applications show a promising potential (Salgueiro-Otero and Ojea, 2020; Arias-Gaviria et al., 2021).

Humans impact ecosystems through management, exploitation, and regulation. The way these

Edited and reviewed by:

George L. W. Perry,

The University of Auckland,

New Zealand

*Correspondence:

Antonio Bodini

antonio.bodini@unipr.it

Specialty section

This article was submitted to

Models in Ecology and Evolution,

a section of the journal

Frontiers in Ecology and Evolution

Received: 29 September 2021

Accepted: 21 October 2021

Published: 19 November 2021

Citation:

Bodini A, Dambacher JM and Jordán F (2021) Editorial: Looking

Through the Mesh of a Net: The

Challenge of Socio-Ecological Systems. Front. Ecol. Evol. 9:785895.

doi: 10.3389/fevo.2021.785895 activities take place depends on the organization of the human society and thus trajectories of ecosystem change reflect social constraints. In turn, ecosystem changes feed back into social relationships creating a subtle interplay that is difficult to recognize and causally understand, but whose comprehension is essential to move toward a sustainable society (Ortiz et al., 2015; Rodriguez et al., 2021).

Causal connections between human society and nature cross the classical boundaries within which scientific and operational knowledge have been established, and this makes understanding socio-ecological dynamics difficult at best. In this special issue, we asked the authors to address these connections and bring to light the complexity triggered by cross-domain interactions. Either methodologically or through the presentation of case studies, the papers collected in this special issue provide a glimpse of the state of the art for socio-ecological analysis. It is clearly far from complete; many key issues pertaining to socio-ecological systems have not been touched upon (i.e., spatio-temporal scales, resilience and climate change, new diseases, and vulnerability of socio-ecological systems). Nevertheless, it is a summary of relevant approaches that are currently in use and exemplifies why research on socio-ecological system is so attractive theoretically, and so promising in practice.

\footnotetext{
${ }^{1}$ Some authors (Berkes, 2017) pointed out that "social-ecological" is more appropriate than "socio-ecological", because the former would assign equal importance to the two subsystems whereas using the latter, as we did in this special issue, would imply a less than equal status of the social subsystem in respect to the ecological one. Here we use the expression socio-ecological but we do not assign any priority and acknowledge the plausibility behind this distinction.
} 


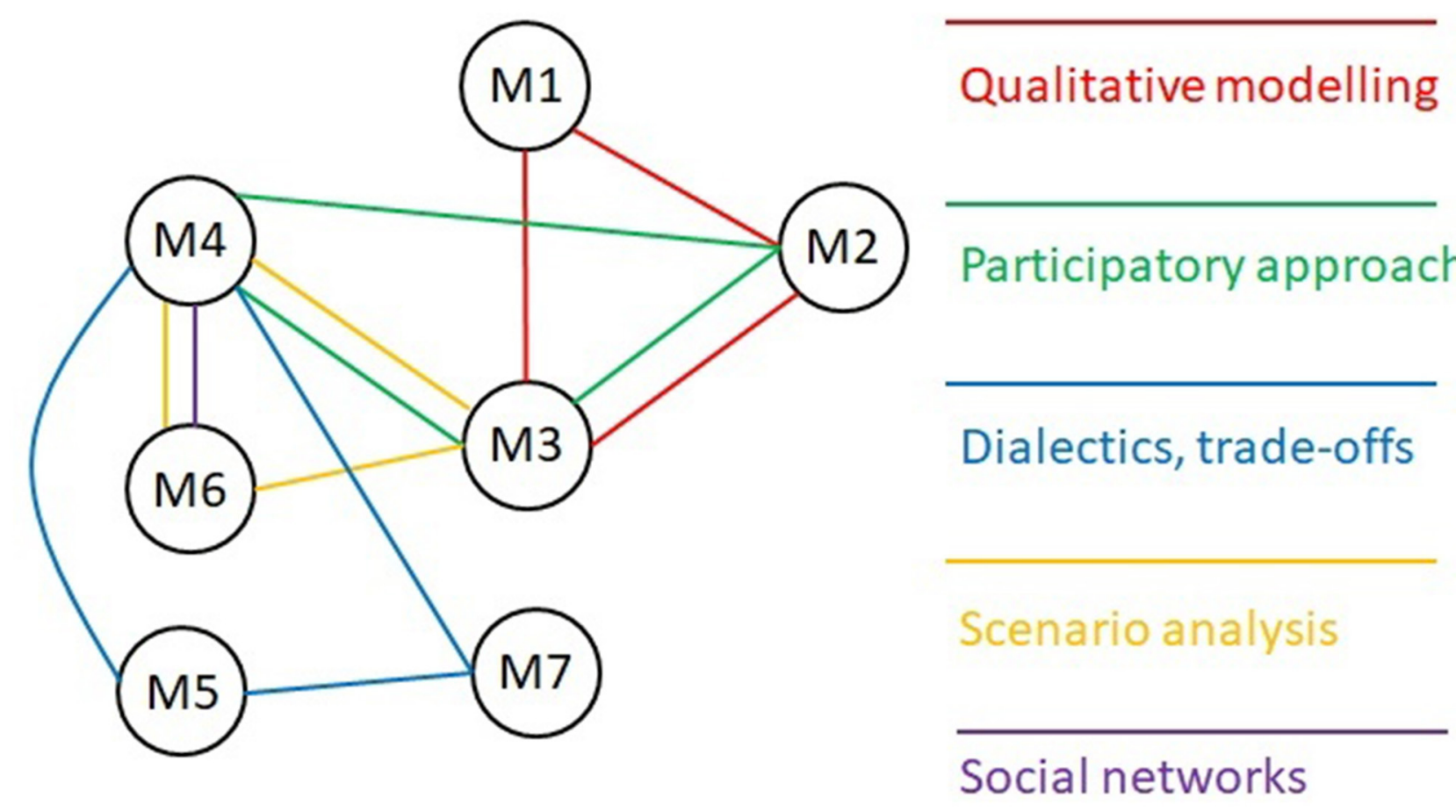

FIGURE 1 | Topical network (left) built around the elements of the socio-ecological research background (in color, on the right) as the contributions forming this essay share them. Directed qualitative links connect any two contributions whenever they share one or more of these elements. Only direct connections are considered. Keys $\mathrm{Mn}$ identify the articles comprised in this Research Topic, as explained in the text.

\section{A NET TO LOOK THROUGH THE MESH OF THE NET}

A methodological challenge that this collection emphasizes is the need for appropriate tools to reveal the complex dynamics that pervade socio-ecological systems. Loop analysis, a qualitative mathematical modeling technique developed by Levins (1974) seems promising in this respect: in our collection three articles of the seven apply this method. Niquil et al. (M1) focus on its flexibility while discussing the SES in which offshore marine farms for energy production are embedded. From system implementation to the operation phase, new networks are organized, with novel actors eventually entering the SES that cause social transformations within local territories, and changes in the environmental biophysics. This evolution has seen new structures emerge in the SES at each step, linking actors to the marine ecosystem in different ways. A rigid (black box simulation) modeling approach would not be as effective in accounting for links and variables that are added or removed as the SES evolves over time.

As Niquil et al. point out, understanding the dynamics of the SES also requires considering human perception and sentiments, which are not easily quantified but nonetheless constitute core elements of the traditional ecological knowledge of local communities. Gourguet et al. (M2) recognize the importance of these core elements to promote sustainability of a shellfish aquaculture socio-ecological system in the Normand-Breton Gulf
(France) and to implement a participatory approach that captures essential links and feedbacks for building qualitative models of that SES. They show that in pursuing advancement toward sustainability of the SES, the knowledge of stakeholders and scientists needs to be integrated in order to construct scenarios and models that are sufficiently realistic. Participatory model building, qualitative loop analysis and scenario analysis are also featured in the Ramos-Jiliberto and Herrera contribution (M3) that develops an approach to sustainable tourism in a Colombian island. Public policies are offered as outcomes of stakeholder experiences, and compared through the response of the SES to the sustained pressures they generate on system components.

Luczkovich et al. (M4) investigate the effects of regulative policies (a gillnet ban) on the SES of the Core Sound area (North Carolina, United States). They combine the social network of fishermen with the food-web (implemented in ECOPATH) in a scenario analysis framework. They highlight that responses in complex SESs may go in the direction opposite to the anticipated management goals. This reveals another central issue in SES dynamics: the perception of causes and effects is confounded by the multiple connections that can make their networks and outcomes counterintuitive. In a review paper, D'Alelio et al. (M5) aggregate and synthesize the scientific information contained in 4,590 peer-reviewed papers and build a topical network, a network of interacting shared concepts. The focus is on multiple socio-ecological processes that are responsible for 
mediated trade-offs between ecosystem services across the aquatic continuum.

Kuslits et al. (M6) highlight the mutual influence between social and ecological elements while discussing management strategies in five protected terrestrial areas in Central and Eastern Europe. Using social network analysis, they show the bidirectional interactions between the social and the ecological realms: ecological processes becoming agents in the SES, such as ecosystem services that influence the structure of management networks and power-relations among stakeholders, and social networks in turn having a significant impact on ecosystem services.

The emergence of counterintuitive, mixed-sign effects, tradeoffs and the presence of conflicting interests is the unavoidable outcome of the dialectics that permeate complex systems (and SESs). The essence of this dialectics is captured by the paper of Ulanowicz (M7), in which autocatalysis and competition, efficiency and reliability, disorder and organization are examples of the unity and struggle of the opposites in socioecological systems.

The articles that this Research Topic comprises share concepts (dialectics, trade-offs) and methods (qualitative analysis, scenario analysis, participatory approach, and social networks). Identifying these features with different colors and connecting with qualitative links of the same color the contributions that share one or more of these elements one can draw a topical

\section{REFERENCES}

Arias-Gaviria, J., Suarez, C. F., Marrero-Trujillo, V., Ochoa, C., Villegas-Palacio, C., and Arango-Aramburo, S. (2021). Drivers and effects of deforestation in Colombia: a system thinking approach. Reg. Environ. Change 21:91. doi: 10.1007/s10113-021-01822-x

Berkes, F. (2017). Environmental governance for the Anthropocene? Socialecological systems, resilience, and collaborative learning. Sustainability 9:1232. doi: $10.3390 /$ su 9071232

Bodin, Ö., and Tengö, M. (2012). Disentangling intangible social-ecological systems. Glob. Environ. Change 22, 430-439. doi: 10.1016/j.gloenvcha.2012.01.005

Colding, J., and Barthel, S. (2019). Exploring the social-ecological systems discourse 20 years later. Ecol. Soc. 24:2. doi: 10.5751/ES-10598-240102

Levins, R. (1974). The qualitative analysis of partially specified systems. Ann. N. Y. Acad. Sci. 231, 123-138. doi: 10.1111/j.1749-6632.1974.tb20562.x

Ortiz, M., Rodriguez-Zaragoza, F., Hermosillo-Nuñez, B., and Jordán, F. (2015). Control strategy scenarios for the alien lionfish pterois volitans in chinchorro bank (Mexican Caribbean): based on semi-quantitative loop analysis. PLoS ONE 10:e0130261. doi: 10.1371/journal.pone.0130261

Rodriguez, M., Bodini, A., Escobedo, F. J., and Clerici, N. (2021). Analyzing socio-ecological interactions through qualitative modeling: Forest conservation and implications for sustainability in the peri-urban bogota (Colombia). Ecol. Model. 439:109344. doi: 10.1016/j.ecolmodel.2020.1 09344 network (sensu D’Alelio, M5) for this Research Topic (Figure 1). It provides a sketch of the intellectual background around which the analysis of socio-ecological systems is shaping. Its linkage structure, in particular, visualizes the importance of the elements of this background as they connect the various papers composing this essay. With the exception of the method of social networks, which connects two contributions (M4 and M6), all the other elements connect three articles. Also, four manuscript of seven (M2, M3, M4, and M6) share more than one element; two of them (M3 and M4) share three elements. The level of connection that characterizes this topical network suggests that the analysis of socio-ecological systems is consolidating around a defined set of methodological and conceptual key words.

\section{AUTHOR CONTRIBUTIONS}

All authors listed have made a substantial, direct, and intellectual contribution to the work and approved it for publication.

\section{ACKNOWLEDGMENTS}

$\mathrm{AB}$ acknowledges that this research was developed in the framework of the COMP-HUB Initiative, within the Departments of Excellence program of the Italian Ministry for Education, University and Research (MIUR, 2018-2022).

Salgueiro-Otero, D., and Ojea, E. (2020). A better understanding of socialecological systems is needed for adapting fisheries to climate change. Marine Policy 122:104123. doi: 10.1016/j.marpol.2020.104123

Scotti, M., Pereira, D., and Bodini, A. (2021). Understanding socialecological systems using loop analysis. Human Ecol. Rev. 26, 39-57. doi: 10.22459/HER.26.02.2020.03

Conflict of Interest: The authors declare that the research was conducted in the absence of any commercial or financial relationships that could be construed as a potential conflict of interest.

Publisher's Note: All claims expressed in this article are solely those of the authors and do not necessarily represent those of their affiliated organizations, or those of the publisher, the editors and the reviewers. Any product that may be evaluated in this article, or claim that may be made by its manufacturer, is not guaranteed or endorsed by the publisher.

Copyright (c) 2021 Bodini, Dambacher and Jordán. This is an open-access article distributed under the terms of the Creative Commons Attribution License (CC BY). The use, distribution or reproduction in other forums is permitted, provided the original author(s) and the copyright owner(s) are credited and that the original publication in this journal is cited, in accordance with accepted academic practice. No use, distribution or reproduction is permitted which does not comply with these terms. 